April - 2016

\title{
Increasing Social Presence in Online Learning through Small Group Discussions
}

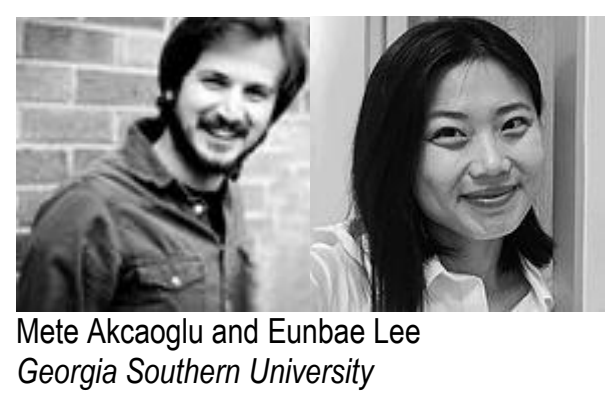

\begin{abstract}
Social presence is difficult to achieve, but an imperative component of online learning. In this study, we investigated the effect of group size on students' perceptions of social presence in two graduate-level online courses, comparing small group versus whole class discussions. Our results indicated that when in small group discussions, students perceived a higher level of social presence in terms of sociability, $t(32)=$ $3.507, p=.001$; social space, $t(29)=3.074, p=.005$; and group cohesion, $t(32)=3.550, p=.001$. We discuss how placing students in small and permanent discussion groups can augment social presence. Designers and educators of online learning can strategically modify group size to promote social presence in asynchronous online discussions.
\end{abstract}

Keywords: online learning, social presence, group size, asynchronous discussion

\section{Introduction}

Establishing social connections is a basic human need. This need extends into online spaces. In fact, even when online, people "are not only looking for information; they are also looking for affiliation, support and affirmation” (Sproull \& Faraj, 1997, p. 38). Similarly, online learning involves social aspects, and social interactions are at the heart of the learning process (Rovai, 2002; Sung \& Mayer, 2012).

In online settings, social interactions are often described by one's perceptions of presence of others. Among various conceptualizations of the term social presence, Short, Williams, and Christie (1976) first defined it as "the degree of salience of the other person in the interaction and the consequent salience of the interpersonal relationships" (p. 65). Social presence is closely linked with the affordances of the online spaces and individual's perceptions of each other's immediacy, intimacy, and a sense of group cohesion (Sung \& Mayer, 2012). 
Social presence, the degree of awareness of others in an interaction (Walther, 1992), is an important aspect of online learning. Research has shown that social interaction is positively linked with learning outcomes (Gunawardena \& Zittle, 1997; Mayer, 2005) and student satisfaction (Borup, West, \& Graham, 2012; Hackman \& Walker, 1990; Richardson \& Swan, 2003; Rourke, Anderson, Garrison, \& Archer, 1999; $\mathrm{Tu}, 2002)$. Social presence also promotes comfort and emotional connections among learners in online learning environments (Aragon, 2003). Perceptions of social presence are influenced by the design and characteristics of online learning contexts (i.e., social affordances; Kreijns, Kirschner, Jochems, \& van Buuren, 2007). In other words, some online learning spaces afford more social interactions, and therefore, are more sociable. In this regard, sociability can be defined as the degree an online learning environment can support the creation of an effective social space where learners trust each other and feel connected with the group.

Despite the popular belief that online learning is task focused and isolated, learners in online settings also need social connections (Kreijns et al., 2007; Wickersham \& Dooley, 2006). Compared to face-to-face learning environments, however, online learning has been criticized as less social, lacking social presence (Rovai, 2002) and non-verbal cues (cf. cues filtered out model by Culnan \& Markus, 1987). Especially, asynchronous learning environments have been argued to put learners at a disadvantage due to physical separation, lack of synchronicity in communication, and text-based nature of the communication (Johnson \& Aragorn, 2003; Rovai, 2002; Sung \& Mayer, 2012).

In text-based asynchronous learning environments, where discussions are designated to be the main context for student-student interaction, design issues (e.g., group size) can influence students' participation or perceptions of connectedness with others (Aragorn, 2003). As one of the design considerations impacting learners' experiences in online learning environments, group size is believed to have a negative impact on group cohesion and student learning (Bertucci, Conte, S. Johnson, \& D. Johnson, 2010; Lowry, Roberts, Romano, Cheney, \& Hightower, 2006). Researchers have identified that, when in larger groups, students are less engaged in higher-order thinking, produce fewer dialogues, and ask fewer questions; discussions are repetitive, and some members may disproportionately dominate the floor (Hamann, Pollock, \& Wilson, 2012). Smaller groups, on the other hand, lead to more opportunities for interactivity and reciprocity and more opportunities for individuals to voice their opinions and contribute to the discussions (Lowry et al., 2006), and promote a sense of community and cohesion (Rovai, 2002).

Previous research has addressed the impact of group size on academic outcomes such as language learners' speaking and writing skills (cf., AbuSeileek, 2012), and critical thinking (Dooley \& Wickersham, 2007). However, there is a dearth of research on the connection between the group size and social presence in online learning. The significance of our research lies on understanding the impact of group size on students' perceptions of social presence in an asynchronous online learning environment. More specifically, the purpose of our research was to understand if students' perceptions regarding social space, group cohesion, and sociability differ depending on the group size in fully online asynchronous learning contexts.

\section{Background}




\section{Group Size}

The size of a social group or a team is related to the complexity of its social interactions (Bertucci et al., 2010). Size can be interpreted as the "number of possible relationships in the group by pairs and larger subgroups rather than the number of persons" (Hare, 1962, p. 228). As size increases, the teamwork becomes more complicated. This complexity introduced by adding more members to a group can be explained by increasing the number of possible social interactions (Hare, 1962). Bertucci et al. (2010) explain this connection between group size and social interactions as "when individuals work in pairs, however, there are two social interactions (i.e., sending and receiving) to manage. When individuals work in fours, there are 12 social interactions to manage. Thus, the larger the group, the more complex the teamwork, and the longer it may take for a group to be productive and cohesive (Bales \& Strodtbeck, 1951; Ortiz, Johnson, \& Johnson, 1996)” (p. 258).

Group size influences social interaction in groups and teams in several ways. In larger groups, dialogue decreases when certain speakers emerge and disproportionately dominate (Hamann et al., 2012; Hare, 1962). This is also known as social loafing, where an increase in the number of members negatively impacts the members' desire and perceptions of responsibility to put effort toward group's goals (Bertucci et al., 2010; Lowry et al., 2006). The increased number of individuals in a group may also impact group member's attention negatively. This is because of the attention overload caused by increased amount of social interactions a group member needs to attend with the addition of each new member (Bertucci et al., 2010). Inevitably, this attention overload negatively impacts members' efforts to complete tasks. In addition, when the group size is large, it is harder and slower for the group members to get to know one another and develop cohesion necessary for teamwork (Bertucci et al., 2010). This leads to a decline in morale and communication quality because intimacy between group members, the strength of interpersonal relationships, and interactivity and reciprocity remains fairly low (Hare, 1962; Lowry et al., 2006). Finally, according to Lowry et al. (2006), in larger groups, members are more likely to experience evaluation apprehension (the fear of being criticized by others) and production blocking (suppression of possibly good ideas due to engagement with group-related processes, e.g., listening to others).

Group size in online learning. In the context of online learning, where learners are limited in social aspects, there are positive outcomes of being in small learning groups. More specifically, in online discussions, smaller groups are more conducive to making connections among students and promote a sense of community (Rovai, 2001; 2002). When placed into discussion groups, information overload and repetitiveness decrease (Qiu, Hewitt, \& Brett, 2014) and the amount of higher-order thinking and learner outcomes increases (Hamann et al., 2012; Wickersham \& Dooley, 2006). In addition, being in smaller groups positively impacts students' communication experiences in terms of their perceptions of the appropriateness and accuracy of messages and their willingness to participate and interact with others (i.e., openness; Lowry et al., 2006).

Furthermore, Qiu et al. (2014) found that although students wrote a greater number of discussion posts when placed in whole class discussions (15-22 students), students produced the higher quality discussion posts (length and reading level) in small group discussions. The data were especially in support of a configuration where small subgroups were created in a large class. Students showed a positive attitude 
toward small subgroups, wrote more, connected more with each other, and indicated that they felt more encouraged to talk; this especially affected students from second language backgrounds.

In another study, AbuSeileek (2012) found that being in small groups, especially groups of five, positively influenced language learners' speaking and listening skills. Compared to groups of six or seven, smaller groups (three, four, five-student groups) had significantly higher achievement in terms of their post-test communication skills. It should be noted, however, that although the students collaborated in a computer-based environment (i.e., students were in a computer lab), this was not an online learning setting.

Dooley and Wickersham (2007) investigated the students' critical thinking skills as they emerged during whole class discussions. The authors identified that when discussions took place in a whole class format, they were often off-topic, certain students dominated the conversation, and critical thinking patterns were either disconnected or very weak. Based on these findings, the authors argued that "through the design of smaller virtual learning communities, students and instructors in online courses are better able to engage in quality discussions with a high degree of interaction, remain focused and on-topic, and better manage the numerous threads that develop within the forums" (p. 7), a finding iterated by an earlier research by the authors (Wickersham \& Dooley, 2006). Similarly, in another study, Hamann, Pollock, and Wilson (2012) compared the effects of being in a large group versus small group on students' perceptions of benefits of discussions. Their analysis showed that when in smaller groups, students perceived the discussions to be more conducive to learning and critical thinking.

Optimal group size. Findings from prior research (e.g., AbuSeileek, 2012; Lowry et al., 2006; Nielsen \& Molich, 1990) provide support and guidance in determining the appropriate group size in communication contexts. In online learning contexts and possibly in other learning contexts, the general tendency is that "too few members generate little interactions [sic] and too many members generate a sense of being overwhelmed" (Rovai, 2002, p. 5). As noted before, this tendency stems from the fact that small groups support building intimacy, while large groups lead its members to withdraw from participation (Qui et al., 2014).

As for a specific group size, Qiu et al. (2014) argue that five is the upper limit for a small group. Supporting the same group size, Hare (1962) also argues that, although optimum size for a group depends on the task, five-person groups can solve problems inherent to smaller and larger groups. Reporting on earlier research, Hare argues that when people are placed into groups smaller than five, they complain that the group is too small. Nielsen and Molich (1990) also support the argument that five is the optimal number of people for evaluation tasks, as beyond five no new information (i.e., identifying errors) is added. Finally, testing different modes (i.e., face-to-face, computer-mediated communication, and faceto-face with computer support), and different groups sizes (three to six members), Lowry et al. (2006) identified that three-person groups significantly outperform six-person groups, where groups with more than five members had significant decreases in communication quality. We, therefore, suggest that small groups should be composed of three to five members to benefit from the positive outcomes of smaller group size.

\section{Social Presence}


The definition of social presence has evolved. Short et al. (1976) defined social presence as "the degree of salience of the other person in the interaction and the consequent salience of the interpersonal relationships" (p. 65). Swan and Shih (2005) emphasized the perception of social presence more than the objective qualities of the medium.

Biocca, Harms, and Burgoon (2003) defined social presence as a "sense of being with another" (p. 456). Lowry's (2006) definition of social presence expanded to the distant, asynchronous, and digital modes:

the degree to which a communication medium allows group members to perceive (sense) the actual presence of the communication participants and the consequent appreciation of an interpersonal relationship, despite the fact that they are located in different places, that they may operate at different times, and that all communication is through digital channels. (p. 633)

Kreijns et al. (2007) defined social presence as "the perceived degree of illusion that the other in the communication appears to be a real physical person in either an immediate (i.e., real time or synchronous) or a delayed (i.e., time-deferred or asynchronous) communication episode" (p. 185). We situate social presence as one's perception of interpersonal relationship she or he creates in online learning environments. When students connect with peers and instructors in the learning environment, they perceive social presence in the learning community.

Social presence is essential for high quality asynchronous discussion forums. That is, high-quality group discussions entail interaction and reciprocity (Burgoon et al., 2002). When students do not participate in a timely manner or the students' discussion posts are ignored, it results in limited interaction and reciprocity and low communication quality, and subsequently, students perceive low social presence. In effect, it can decrease the quality of student performance (Lowry et al., 2006).

Social presence is believed to be composed of certain components (e.g., Biocca et al., 2003). According to Kreijns et al. (2007), social presence is influenced by the following factors: sociability (leads to increases in social interaction), group cohesion (increases in group awareness contributes to perceptions of presence), and social space (the social affordances of a learning environment leads to increased social interactions). In the following section, we define the three constructs and introduce the hypotheses of the study.

Sociability. Sociability, contributing to social presence, refers to "a strength or potential associated with an environment” (p. 14) for facilitating emergence of social interactions (Kreijns, Kirschner, \& Jochems, 2002). Sociability is, therefore, a characteristic of an online learning environment and can be defined as "the extent to which the environment is perceived to be able to facilitate emergence of social interactions" (Kreijns et al., 2007, p. 176). Sociable environments enable and facilitate affiliation, interpersonal relationships, trust, respect, satisfaction, social cohesiveness, and good working relationships, and cohesion (Kreijns et al., 2002; Kreijns, Kirschner, \& Vermeulen, 2013).

Several factors determine the sociability of online learning. Social climate, the community of students, the richness of the interaction, benefits and purposes, and support for formal interactions affect perceived sociability of the learning environment (Gao, Dai, Fan, \& Kang, 2010). Additionally, students' perceptions 
of their self-representation and their compatibility with the learning environment can also influence sociability of academic or non-academic tasks in a computer-mediated learning environment (Abedin, Daneshgar, \& D’Ambra, 2012).

Technological affordances are also major determining factors of sociability in online learning environments (cf. Gao, Dai, Fan, \& Kang, 2010). Design and implementation of technological features can motivate and sustain socially meaningful interactions and learner satisfaction (Laffey, Lin, \& Lin, 2006). As online discussion forums are a technological feature to facilitate interactions among students and, in turn, relationship-building (Yen \& $\mathrm{Tu}, 2011$ ), how to design the discussion forum interactions is an important instructional decision. However, limited research exists on design decisions on how to enhance sociability of the online environment, particularly with regard to group size. Linking with the impacts of group size in online learning, we hypothesize that the smaller the discussion group sizes, the more sociability students perceive of their online learning environments.

○ Hypothesis 1: Smaller group discussions will lead to higher sociability perceptions.

Social space. Social space refers to the "the network of social relationships amongst the group members embedded in group structures of norms and values, rules and roles, beliefs and ideals (Kreijns, Kirschner, Jochems, \& Van Buuren, 2004, p. 608). As a construct, social space has a variety of nomenclature, referred as social climate by Gunawardena and Zittle (1997), social environment by Rourke et al. (1999), and online atmosphere by Brandon and Hollingshead (1999).

Social space is positively influenced by affective aspects of interpersonal relationships in a group, such as group cohesiveness, trust, respect, and belonging (Kreijns et al., 2004). Social space, in turn, influences social interaction, leading to opportunities for critical dialogue, where open communication is not offensive or harmful thanks to the trust and sense of community among members. The open flow of information helps increase members' commitment to group goals and satisfaction with the group (Kreijns et al., 2004). In sum, "a sound social space contributes to a positive social climate/online-atmosphere within the group (Brandon \& Hollingshead, 1999; Rourke, 2000; Rourke \& Anderson, 2002)" (Kreijns et al., 2004, p. 608).

As constructs of social presence, social space and sociability are moderately correlated (Kreijns et al., 2007). According to Kreijns et al. (2002), low sociability of a group negatively impacts the emergence of social space. In other words, sociability contributes to social space, but the two constructs measure different aspects of the social interactions in groups, as indicated by the moderate level of correlations in previous research (Kreijns et al., 2007).

During asynchronous online discussions, emergence of social space is believed to be influenced by the members of the community (Kreijns et al., 2013). In other words, the members can decide whether to pursue the group's goals, or utilize the affordances of the learning environment (i.e., sociability). Aspects of social spaces that contribute to social space perceptions is, however, unknown. Especially, we do not know if group size functions as a social affordance and contributes to social space perceptions during asynchronous online discussions. Based on previous work on group size, we hypothesize that the smaller the discussion group sizes, the more positive the students' perceptions of social space. 
○ Hypothesis 2: Smaller group discussions will lead to more positive social space perceptions.

Cohesion. Cohesion can be defined as a group's sense of commitment and closeness with other group members (Borup et al., 2012), the we feeling (Qui et al., 2014), and is considered to be a component of social space (Kreijns et al., 2004). Cohesion indicates the amount of close friends and friendship in people's immediate work environment (Price \& Mueller, 1986). Similarly, in an online learning context learners are expected to form friendships (Kreijns et al., 2004).

Due to the distributed and diverse nature of online learning contexts, researchers were not able to identify benefits from small group work, contrary to the findings from face-to-face learning contexts (Qui et al., 2014). According to Milliken and Martins (1996), diversity in online settings is one factor that leads to these negative findings, where diversity arguably leads to dissatisfaction among members and failure to identify themselves with the group.

Design of online learning environments can influence group cohesiveness. For example, accountability and interdependence levels can be adjusted to achieve more cohesive groups (Qui et al., 2014). In terms of technical aspects (i.e., group size), researchers believe that small groups may negatively impact member's perceptions of collaboration, by making individual differences among group members more salient. Despite this belief, we contend that in online learning settings, despite the inherent diversity, the learners are often task focused. We believe by placing individuals into smaller groups, we can reduce negative aspects of online learning (e.g., social loafing, low levels of group cohesion). As argued by Qiu, Hewitt, and Brett (2014), "many online instructors do not pay enough attention to group size or organization in their course planning. Failure to consider group cohesion due to group configuration can lead to unsuccessful online discourse" (p. 290). Based on previous work on group size, we hypothesize that the smaller group discussion will positively influence students' perceptions of group cohesion.

○ Hypothesis 3: Smaller group discussions will lead to increased group cohesion perceptions.

\section{The Present Study}

Discussion forums in online courses provide a context for interaction. Especially in graduate level courses, these asynchronous communication tools are used widely. There is limited amount of research in the context of online learning examining the relationship between group size and aspects of social presence. In this study, our purpose is to examine the effect of group size on students' perceptions of social space, group cohesion, and sociability in an asynchronous online discussion environment. More specifically, our research question is:

- Does the size of online discussion groups influence students' perceptions of social space, group cohesion, and sociability?

This study carries importance in pointing to instructional design decisions regarding social aspects of online learning environments.

\section{Methods}




\section{Context and Participants}

Participants in this study $(n=33)$ were graduate students pursuing a master's degree in education and were enrolled in a fully online and asynchronous masters course on Assessment and Data Analysis in Teaching at a comprehensive university in the southeastern region of the United States. The data were collected from two groups of students when the course was offered in two consecutive semesters, Fall $2014(n=17)$ and Spring $2015(n=16)$. Both the content and the instructor of the course remained the same for the two iterations.

\section{Instruments}

The survey included three instruments: Work Group Cohesion Index (Price \& Mueller, 1986), Sociability Scale (Kreijns et al., 2007), and Positive Social Space Scale (Kreijns et al., 2004). The reliability of the full survey (composed of the three subscales) was .974 .

The Work Group Cohesion Index, developed by Price and Mueller (1986), was used to measure workgroup cohesion in organizational contexts. The Work Group Cohesion Index consisted of five, 5point Likert scale items (e.g., "To what extent were your group mates friendly?”). The reliability for this subscale was high, $\alpha=.838$.

The Sociability Scale (Kreijns et al., 2007) was originally designed to determine the perceived degree of sociability of computer supported collaborative learning (CSCL) environments (e.g., "This discussion environment enables me to develop good work relationships with my team mates"). We adopted this 10item scale to measure the sociability of the asynchronous online text-based discussion environment. While students did not conduct a collaborative project, the scale provided the measure for the functions of the learning environment in light of sociability. It was a one-dimensional scale consisting of 10 items. Cronbach's $a$ for the Sociability Scale revealed a high internal consistency, $a=953$.

The Social Space Scale, developed by Kreijns et al. (2004), was composed of 10 items, designed to measure the quality of the social space in asynchronous learning environments (e.g., "We reached a good understanding on how we had to function"). Although the original scale had two dimensions (positive and negative group behavior), we chose to only include the positive dimension because the items in the negative scale were not amenable to our learning environment (e.g., "Group members grew to dislike others."). The reliability for this subscale was high, $a=947$.

\section{Procedures}

To give all participants an equal chance of exposure to both the small groups and the large (whole-class) group discussions, the participants were first placed in a whole class discussion for the first part of the semester (Weeks 1-4). Following this, the participants were randomly placed into permanent groups of four to five members for the following four weeks (Weeks 5-8). During the weekly discussions, the participants were required to post their thoughts on reading-related questions that were posed by the instructor. In addition, students were required to post a response to at least one of their class or group mate's original post. Students were graded on the quality of initial posts and the responses. 
After the students experienced both versions of the discussions, an online survey was sent to the students starting Week 9. The survey asked the participants to compare the large group and the small group implementations in terms of their perceptions of group cohesion, sociability, and social space (Figure 1). For each survey item the students selected a value (out of 5) to indicate their perceptions of the small group and whole-class implementations separately.

\begin{tabular}{l|ccccc|ccccc} 
& $\begin{array}{c}\text { When I was in the whole } \\
\text { class discussions }\end{array}$ & \multicolumn{4}{|c}{$\begin{array}{c}\text { When I was in the small } \\
\text { group discussions }\end{array}$} \\
& 1 & 2 & 3 & 4 & 5 & 1 & 2 & 3 & 4 & 5 \\
\hline $\begin{array}{l}\text { To what extent were the other members } \\
\text { friendly? }\end{array}$ & 0 & 0 & 0 & 0 & $\bigcirc$ & $\bigcirc$ & 0 & 0 & $\bigcirc$ & 0
\end{tabular}

Figure 1. Screen capture of the example survey item.

\section{Data Analysis}

To understand if the students in the two implementations (i.e., fall and spring semesters) were equivalent in terms of their perceptions, and thus be treated as one sample, we ran independent $t$ tests comparing the two implementations. The results of the $t$ test indicated that the two implementations did not differ in terms of students' perceptions of the three constructs when placed in a large (i.e., whole class discussions) or a small group (i.e., discussions in a permanent group of four to five members): cohesion: whole class: $t(31)=.385, p=.703$; small: $t(31)=.693, p=.493$; sociability: whole class: $t(31)=.385, p=.703$, small: $t(31)=.383, p=.315$; and social space: whole class: $t(28)=.958, p=.346$, small: $t(28)=.806, p=.427$. Based on this finding, we merged the data from the two implementations and conducted the remaining between-subjects analyses (i.e., paired-samples $t$ test) on this combined sample.

\section{Results}

\section{Sociability}

A statistically significant difference was observed between the small group and large group discussions in terms of students' perceptions of sociability, $t(32)=3.507, p=.001$. As indicated in Table 1 , students rated sociability higher for the small group discussions $(M=4.05, S D=.74)$ than large groups $(M=3.65$, $S D=.92)$. The effect size for the difference was sizable, Cohen's $d=.61$. This result supported our hypothesis: students perceived that small discussion groups facilitated higher levels of social interactions.

\section{Social Space}

With regard to social space, there was a statistically significant difference between small and large group discussions, $t(29)=3.074, p=.005$. Small group discussions $(M=3.64, S D=.74)$ were perceived to be more conducive to building positive relationships than whole class discussions $(M=3.27, S D=.99)$. There was a medium effect size for the difference, Cohen's $d=.56$. This result supported our hypothesis: small discussion groups led to more positive perceptions of social space.

\section{Cohesion}


Our results indicated that there was a significant difference in the students' perceptions of the large and the small group implementations in terms of group cohesion, $t(32)=3.55, p=.001$. The results indicated that students perceived small groups $(M=4.06, S D=.51)$ to be more conducive to cohesion than large groups $(M=3.75, S D=.65)$. There was a medium effect size for the difference, Cohen's $d=.61$. Our hypothesis was supported that when in smaller discussion groups, students felt a stronger sense of commitment and closer to other group members.

Table 1

Descriptive Statistics for Group Cohesion, Sociability, and Social Space

\begin{tabular}{llllllll}
\hline & $N$ & \multicolumn{1}{c}{$M$} & & \multicolumn{2}{c}{$S D$} \\
\cline { 1 - 3 } \cline { 6 - 7 } Sociability & 33 & & LG & SG & & LG & SG \\
Social space & 30 & & 3.65 & 4.05 & & .92 & .74 \\
Cohesion & 33 & 3.75 & 4.06 & & .65 & .51 \\
\hline
\end{tabular}

Note. $\mathrm{LG}=$ large group, $\mathrm{SG}=$ small group

\section{Student Reflections of Group Sizes}

At the end of the survey, the students also had a chance to explain their preferences regarding the group size of in-class discussions by answering an open-ended question: "Any other thoughts on the difference between being in small groups during discussions vs. large groups (i.e., whole class)?” Out of the 33 participants, close to a half of the participants $(n=16)$ provided a response to this question. In order to identify common themes in student responses, we used deductive coding analysis and categorized the codes into themes (Corbin \& Strauss, 2008). Key words or phrases that best represented the overall type of statement were selected as overarching themes (see Table 2).

Table 2

Themes Emerged from Students' Opinions Regarding Small and Whole Class Discussions

\begin{tabular}{lc}
\hline Theme & Frequency \\
\hline Small Group & \\
sensitive to member participation (timeliness in posts) (-) & 4 \\
get to know others (+) & 4 \\
narrow (easy) focus (+) & 4 \\
engage/think more (+) & 3 \\
build a history (+) & 2 \\
Whole Class & \\
more feedback/opinions (+) & 5 \\
\hline
\end{tabular}


less personal (-) 1

posts may go unread (-) 1

lots of voice (-)

Administration

group member selection

provide a mix of whole class (beginning of semester) and small

group (later in the semester)

Note. (+) indicates a positive opinion, (-) indicates a negative opinion.

Students indicated that being in small discussion groups had a significant number of benefits. They said with fewer members it was easier for them to get to know one another, engage in deeper conversations, and think more deeply. As indicated by one participant, smaller groups enabled participants to get to know each other better: "I felt as though I became very familiar with another student's ideas and thoughts when I was in a small group of four." It was indicated that when in smaller discussion groups, students felt the urge to "to think more and really participate." Students also indicated that being in the same small discussion group throughout the semester enabled them to build a group history: "This format allows us to connect more to previous conversations instead of having to rehash material that was discussed in earlier conversations."

One caveat mentioned by students was that in small group discussions group members' timeliness was very important. As indicated by one student, late participation negatively impacted richness of the discussions: "The small group is very limiting in my opinion because some members of my group do not post until late Saturday and sometimes late Sunday, which provides a disconnect for me with the content since I reply on Monday. There is no discussion until those other members have replied." As another student indicated: "It's hard to have a discussion with yourself," and therefore, small discussion groups were more sensitive to member's timely and active participation.

As for the whole class discussions, students indicated that having a large amount of posts each week actually was a positive attribute in that it allowed them to see a wide range of opinions. One student explained this preference: "I like the large group discussions because you get more feedback than you do when in a small group. You also get more options of people to respond to." The volume of posts, however, was a negative outcome of whole class discussions, especially for social presence. For example, as indicated by one student, in whole class discussions "there is a lot less direct/personal communication in posts." In addition, it was noted that due to a large amount of posting "sometimes your post may tend to go unread by others and you may feel as if you wasted your time writing the post."

Students also pointed to some organizational and implementation-specific aspects of small group discussions. For example, students indicated that allowing members to select each other, or being placed into groups where people shared common backgrounds (e.g., preschool teachers) could allow for more networking opportunities. One student also noted that depending on the time of the semester, whole class or small group discussions can be selected. More specifically, it was indicated that "At the very beginning 
of a class, a large discussion is appropriate for the purpose of introductions . . . smaller discussion groups [works better] as the class progresses."

\section{Discussion}

The purpose of this study was to understand if group size during online discussions was a factor influencing students' perceptions of social presence in asynchronous online learning contexts. Although previous research identified how group size can impact communication quality or learning outcomes, our findings extend that group size in asynchronous online discussions influence students' perception of social presence; smaller groups are more amenable to building interpersonal relationships with other participants and help members come together on common goals (Jaques \& Salmon, 2007).

Based on our results, similar to Rovai (2002), we argue that small group work promotes a sense of community, as a result of the increased interaction time devoted to each member. Our results indicated that when placed in small permanent discussion groups, the students perceived the online learning context to (a) be more sociable, (b) have a more positive atmosphere, and (c) afford group cohesion more easily. Students also noted that in smaller groups they felt closer to each other, whereas during whole class discussions it was hard for them to keep track of all the posts and develop impressions of the classmates. These results point to the positive aspects of small group work in online classrooms, reiterating the importance of how design of online learning spaces (i.e., group size) can have significant impacts on students' perceptions of social presence (Swan \& Shih, 2005).

While collaborative problem solving (e.g., computer supported collaborative learning) is increasingly implemented in online courses, asynchronous discussions are commonly used for communication and interaction among class members (Dooley \& Wickersham, 2007). For example, in our cases, the only interaction in this online learning environment was facilitated through an online discussion forum. These weekly interactions may not be necessarily built to facilitate collaboration and may not support social presence and member interactions. They are usually in the form of idea exchange on given topics, but not necessarily team-problem-solving or collaborative projects, which would require more complex interactions and shared responsibilities from the participants. In such cases where collaboration is not a part of the course (e.g., weekly post-and-forget type discussions), our study proposes that the adjustment to group configuration can alleviate possible social presence-related problems in asynchronous online courses.

\section{Limitations}

There are some limitations to the present study. First, it should be noted that this study was not an experimental study and conducted on a small sample. As typical in classroom research, randomization of participants was not feasible. Therefore, our results should be interpreted with caution. In addition, the order the students experienced the group sizes (first large, then small) might have impacted students' perceptions to be more in favor of the recent experience (i.e., priming effect). Similarly, due to this order, time spent on the course might have been positively influenced the small group interactions. It should be also noted that the participants in this study were graduate students, and may therefore, differ from other 
learner populations. The generalizability of our results, and the interpretation of the findings, should be done with these limitations in mind.

\section{Conclusions and Future Studies}

When placed in large discussion groups, although one might falsely get the impression that deep discussions and social bonding is taking place solely by looking at the large number of posts (Wickersham \& Dooley, 2006), the students may, in fact, have a hard time connecting with their peers due to low social interdependence, process losses, and social loafing caused by the volume of submissions (Lowry et al., 2006). Given the only and most prevalent social interaction opportunity is discussions for many online courses, examining conditions to increase their ability to support students socially and emotionally carries importance. Our results suggest that by manipulating group size, students' perceptions of cohesion, and sociability were positively increased in asynchronous class discussions.

While we were able to contribute to theory and research on social presence and sociability, some questions remain for future research. For example, our primary limitation (order effect) should be investigated in future studies. Results from such work would both benefit research and practice, in that importance of time as a factor affecting group configurations can be identified. Investigating learning outcomes was beyond the scope of this research. Future research, therefore, should also focus on the impact of social presence on learning outcomes. For example, through a qualitative analysis of student posts, the amount of social presence and higher-order thinking can be identified (e.g., Wickersham \& Dooley, 2006).

As argued by Kreijns et al. (2013), we contend that environmental characteristics and instructional techniques facilitate students' interactions in online courses, which in turn, influences the degree of perceived social presence. By decreasing the number of interactions to follow, small group discussions seem to support formation of better personal impressions of group members, their ability to work together, and perceptions of sociability of the online learning environment. Therefore, through our work, we introduce group size as one of the factors contributing to sociability, social space, and group cohesion.

\section{References}

Abedin, B., Daneshgar, F., \& D’Ambra, J. (2012). Do non-task interactions matter? The relationship between non-task sociability of computer supported collaborative learning and learning outcomes. British Journal of Educational Technology, 43, 385-397. Retrieved from http://dx.doi.org/10.1111/j.1467-8535.2011.01181.x

AbuSeileek, A. F. (2012). The effect of computer-assisted cooperative learning methods and group size on the EFL learners' achievement in communication skills. Computers and Education, 58(1), 231-239. Retrieved from http://dx.doi.org/10.1016/j.compedu.2011.07.011

Aragon, S. R. (2003). Creating social presence in online environments. New Directions for Adult and Continuing Education, 100, 57-68. Retrieved from http://dx.doi.org/10.1002/ace.119 
Bertucci, A., Conte, S., Johnson, D. W., \& Johnson, R. T. (2010). The impact of size of cooperative group on achievement, social support, and self-esteem. The Journal of General Psychology: Experimental, Psychological, and Comparative Psychology, 137(3), 256-272. Retrieved from http://dx.doi.org/10.1080/00221309.2010.484448

Biocca, F., Harms, C., \& Burgoon, J. (2003). Toward a more robust theory and measure of social presence: Review and suggested criteria. Presence, 12(5), 456-480. Retrieved from http://dx.doi.org/10.1162/105474603322761270

Burgoon, J. K., Bonito, J., Ramirez, A., Kam, K., Dunbar, N. E., \& Fischer, J. (2002). Testing the interactivity principle: Effects of mediation, propinquity, and verbal and nonverbal modalities in interpersonal interaction. Journal of Communication, 52(3), 657-677. Retrieved from http://dx.doi.org/10.1093/joc/52.3.657

Borup, J., West, R. E., \& Graham, C. R. (2012). Improving online social presence through asynchronous video. The Internet and Higher Education, 15(3), 195-203. Retrieved from http://dx.doi.org/10.1016/j.iheduc.2011.11.001

Brandon, D. P., \& Hollingshead, A. B. (1999). Collaborative learning and computer-supported groups. Communication Education, 48(2), 109-126. Retrieved from http://dx.doi.org/10.1080/03634529909379159

Corbin, J., \& Strauss, A. (2008). Basics of qualitative research. Thousand Oaks, CA: Sage.

Culnan, M. J., \& Markus, M. L. (1987). Information technologies. In F. M. Jablin, L. L. Putnam, K. H. Roberts, \& L. W. Porter (Eds.), Handbook of organizational communication: An interdisciplinary perspective (pp. 420-443). Newbury Park, CA: Sage.

Dooley, K. E., \& Wickersham, L. E. (2007). Distraction, domination, and disconnection in whole-class online discussions. Quarterly Review of Distance Education, 8(1), 1-8.

Gao, Q., Dai, Y., Fan, Z., \& Kang, R. (2010). Understanding factors affecting perceived sociability of social software. Computers in Human Behavior, 26, 1846-1861. Retrieved from http://dx.doi.org/10.1016/j.chb.2010.07.022

Gunawardena, C. N., \& Zittle, F. J. (1997). Social presence as a predictor of satisfaction within a computer-mediated conferencing environment. The American Journal of Distance Education, 11(3), 8-26. Retrieved from http://dx.doi.org/10.1080/08923649709526970

Hackman, M. Z., \& Walker, K. B. (1990) Instructional communication in the televised classroom: The effects of system design and teacher immediacy on student learning and satisfaction. Communication Education, 39(3), 196-209. Retrieved from http://dx.doi.org/10.1080/03634529009378802

Hare, A. P. (1962). Handbook of small group research. New York, NY: The Free Press of Glencoe. 
Hamann, K., Pollock, P. H., \& Wilson, B. M. (2012). Assessing student perceptions of the benefits of discussions in small-group, large-class, and online learning contexts. College Teaching, 6o(2), 65-75. Retrieved from http://dx.doi.org/10.1080/87567555.2011.633407

Jaques, D., \& Salmon, G. (2007). Learning in groups: A handbook for face-to-face and online environments. New York, NY: Routledge.

Johnson, S. D., \& Aragon, S. R. (2003). An instructional strategy framework for online learning environments. In S. R. Aragon (Ed.), Facilitating learning in online environments (pp. 31-43). San Francisco, CA: Jossey-Bass.

Kreijns, K., Kirschner, P. A., \& Jochems, W. (2002). The sociability of computer-supported collaborative learning environments. Educational Technology \& Society, 5(1), 8-22.

Kreijns, K., Kirschner, P. A., Jochems, W., \& Van Buuren, H. (2004). Determining sociability, social space, and social presence in (a) synchronous collaborative groups. Cyberpsychology \& Behavior, 7(2), 155-172. Retrieved from http://dx.doi.org/10.1089/109493104323024429

Kreijns, K., Kirschner, P. A., Jochems, W., \& Van Buuren, H. (2007). Measuring perceived sociability of computer-supported collaborative learning environments. Computers \& Education, 49(2), 176192. Retrieved from http://dx.doi.org/10.1016/j.compedu.2005.05.004

Kreijns, K., Kirschner, P. A., \& Vermeulen, M. (2013). Social aspects of CSCL environments: A research framework. Educational Psychologist, 48(4), 229-242. Retrieved from http://dx.doi.org/10.1080/00461520.2012.750225

Laffey, J., Lin, G. Y., \& Lin, Y.M. (2006). Assessing social ability in online learning environments. Journal of Interactive Learning Research, 17(2), 163-177.

Lowry, P. B., Roberts, T. L., Romano, N. C., Cheney, P. D., \& Hightower, R. T. (2006). The impact of group size and social presence on small-group communication: Does computer-mediated communication make a difference? Small Group Research, 37(6), 631-661. Retrieved from http://dx.doi.org/10.1177/1046496406294322

Mayer, R. E. (2005). Principles of multimedia learning based on social cues: Personalization, voice and image principles. In R. E. Mayer (Ed.), The Cambridge handbook of multimedia learning (pp. 201-212). New York, NY: Cambridge University Press.

Milliken, F. J., \& Martins, L. (1996). Searching for common threads: Understanding the multiple effects of diversity in organizational groups. Academy of Management Review, 21, 402-433.

Retrieved from http://dx.doi.org/10.2307/258667

Nielsen, J., \& Molich, R. (1990). Heuristic evaluation of user interfaces. In Proceedings of the SIGCHI conference on Human factors in computing systems (pp. 249-256). New York: ACM. Retrieved from http://dx.doi.org/10.1145/97243.97281 
Qiu, M., Hewitt, J., \& Brett, C. (2014). Influence of group configuration on online discourse writing. Computers and Education, 71, 289-302. doi:10.1016/j.compedu.2013.09.010

Price, J. L., \& Mueller, C. W. (1986). Handbook of organizational measurement. Marshfield, MA: Pitman.

Richardson, J. C., \& Swan, K. (2003). Examining social presence in online courses in relation to students' perceived learning and satisfaction. Journal of Asynchronous Learning Networks, 7(1), 68-88. Retrieved from http://hdl.handle.net/2142/18713

Rourke, L. (2000). Operationalizing social interaction in computer conferencing. In Proceedings of the 16th Annual conference of the Canadian Association for Distance Education. Quebec City.

Rourke, L., \& Anderson, T. (2002). Exploring social communication in computer conferencing. Journal of Interactive Learning Research, 13(3), 259-275.

Rourke, L., Anderson, T., Garrison, D. R., \& Archer, W. (1999). Assessing social presence in asynchronous, text-based computer conferences. Journal of Distance Education, 14(3), 51-70.

Rovai, A. P. (2001). Building classroom community at a distance: A case study. Educational Technology Research and Development Journal, 49(4), 33-48. Retrieved from http://dx.doi.org/10.1007/bfo2504946

Rovai, A. P. (2002). Building sense of community at a distance. The International Review of Research in Open and Distributed Learning, 3(1). Retrieved from http://www.irrodl.org/index.php/irrodl/article/view/79/152

Short, J., Williams, E., \& Christie, B. (1976). The social psychology of telecommunications. London, UK: John Wiley \& Sons.

Sproull, L., \& Faraj, S. (1997). Atheism, sex, and databases: The net as a social technology. In S. Kiesler (Ed.), Culture of the internet (pp. 35-52). Mahwah, NJ: Lawrence Erlbaum.

Sung, E., \& Mayer, R. E. (2012). Five facets of social presence in online distance education. Computers in Human Behavior, 28(5), 1738-1747. Retrieved from http://dx.doi.org/10.1016/j.chb.2012.04.014

Swan, K., \& Shih, L. F. (2005). On the nature and development of social presence in online discussions. Journal of Asynchronous Learning Networks, 9(3), 115-136.

Tu, C. H. (2002). The measurement of social presence in an online learning environment. International Journal on E-Learning, 1(2), 34-45.

Walther, J. B. (1992). Interpersonal effects in computer-mediated interaction: A relational perspective. Communication Research, 19(1), 52. Retrieved from http://dx.doi.org/10.1177/009365092019001003 
Wickersham, L. E., \& Dooley, K. E. (2006). A content analysis of critical thinking skills as an indicator of quality of online discussion in virtual learning communities. Quarterly Review of Distance Education, 7(2), 185-193.

Yen, C., \& Tu, C. (2011). A multiple-group confirmatory factor analysis of the scores for online presence: Do they measure the same thing across cultural groups? Educational Computing Research, 44(2), 219-242. http://dx.doi.org/10.2190/ec.44.2.e

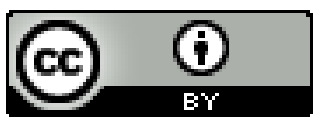

